\title{
THE ISSUES OF THE FORMATION OF THE COMMON ECONOMIC INTEREST IN THE RUSSIAN ECONOMIC SYSTEM ${ }^{1}$
}

\author{
Aleksej M. Tsikin \\ Financial University under the Government of the Russian Federation, Moscow, Russian Federation
}

\begin{abstract}
The article is devoted to studying the theory of economic interests on the basis of the retrospective analysis of the works of the main economic school representatives, modern Russian and foreign scientists. The aim of the work is to elaborate the concept of the common economic interest in the modern Russian economic system. To achieve this aim, the author conducted the development analysis of the relevant methodological approaches to the study of economic relations, identified the most relevant concepts and proposed the concept interpretations of the national economic system priorities. It is established that the evolution of the theory of economic interests is directly related to the world economy development. In the current conditions, approaches related to absolutization of state (characteristic of the Late Middle Ages) or private (used during the rapid development of the market) interests are not applicable to achieve the common economic interest. Today, the theory introduces the factors of uncertainty, limited knowledge, explores real and perceived interests, and increases the role of social security and environmental safety. The analysis carried out in the work indicates the need to include social, innovative, technological, labor, infrastructure, institutional priorities, as well as self-sufficiency of the economy in the definition of the common economic interest. The results of the work can be used in developing strategies to improve the competitiveness of the Russian economy.
\end{abstract}

Key words: economic interests, competitiveness, national economy, economic policy, economic growth.

Citation. Tsikin A.M. The Issues of the Formation of the Common Economic Interest in the Russian Economic System. Vestnik Volgogradskogo gosudarstvennogo universiteta. Seriya 3, Ekonomika. Ekologiya [Science Journal of Volgograd State University. Global Economic System], 2019, vol. 21, no. 2, pp. 34-43. (in Russian). DOI: https://doi.org/10.15688/jvolsu3.2019.2.3

УДК 330.161

Дата поступления статьи: 30.03.2019

ББК 65.01 Дата принятия статьи: 15.04.2019

\section{ПРОБЛЕМЫ ФОРМИРОВАНИЯ ОБЩЕГО ЭКОНОМИЧЕСКОГО ИНТЕРЕСА В РОССИЙСКОЙ ЭКОНОМИЧЕСКОЙ СИСТЕМЕ ${ }^{1}$}

\author{
Алексей Максимович Цикин \\ Финансовый университет при Правительстве РФ, г. Москва, Российская Федерация
}

\begin{abstract}
Аннотация. Статья посвящена исследованию эволюции теории экономических интересов на основании ретроспективного анализа трудов представителей основных экономических школ, современных российских и зарубежных ученых. Целью работы является детализация понятия общего экономического интереса в современной российской экономической системе. Для ее достижения проведен анализ развития соответствующих методологических подходов к изучению экономических отношений, выявлены наиболее релевантные концепции и предложена концептуальная трактовка приоритетов национальной экономической системы. Установлено, что эволюция теории экономических интересов непосредственно связана с развитием м мировой экономики: в современных условиях для достижения общего экономического интереса непримен нимы подходы, связанные с абсолютизацией государственных (характерных для Позднего Средневековья) или частных (используемых во время бурного развития рынка) интересов. Сегодня в теорию вводятся факторы неопределенности, ограниченности знаний, исследуются реальные и мнимые интересы, повышается () роль социальной защищенности и экологической безопасности. Проведенный анализ свидетельствует о не-
\end{abstract}


обходимости включения в определение общего экономического интереса социальных, инновационных, технологических, трудовых, инфраструктурных, институциональных факторов, а также самодостаточности экономики. Результаты исследования могут быть использованы при разработке стратегий повышения конкурентоспособности российской экономики.

Ключевые слова: экономические интересы, конкурентоспособность, национальная экономика, экономическая политика, экономический рост.

Цитирование. Цикин А. М. Проблемы формирования общего экономического интереса в российской экономической системе // Вестник Волгоградского государственного университета. Серия 3, Экономика. Экология. - 2019. - Т. 21, № 2. - C. 34-43. - DOI: https://doi.org/10.15688/jvolsu3.2019.2.3

\section{Введение}

Современное состояние российской экономической системы характеризуется высокой неопределенностью и противоречивостью факторов развития. Одна из причин нереализуемости на практике предложенных учеными моделей развития национальной экономики заключается в искаженной системе стимулов хозяйственной деятельности. На основании этих соображений Дж. Дози выделяет проблему координации экономических интересов агентов рынка как один из ключевых вопросов всей экономической науки [Дози, 2012].

Дисбалансы и противоречия в экономических интересах субъектов рынка, сформированные в результате приватизационных процессов в России после распада СССР, сегодня находятся в новой стадии обострения [Афонцев и др., 2013]. Текущая российская экономическая политика может привести к ситуации, когда приоритетными выступают нерыночные решения, снижающие конкурентоспособность национальной экономики. Одним из объяснений является тот факт, что современная экономическая система России сформировалась на основе неоклассических постулатов о минимизации участия государства в управлении экономикой и формирования своеобразной «амальгамы» из чиновников и представителей крупного бизнеса [Пороховский, 2008].

Сращивание крупного бизнеса и бюрократии в российских реалиях приводит к тому, что бизнес использует административный ресурс для ускорения и повышения эффективности решений, что приводит к искажению моделей конкуренции и вытеснению конкурентоспособных агентов [Андреев, 2006]. В современной России наиболее конкурентоспособным является бизнес, основанный на потреблении государственных, в первую очередь финансовых, ресурсов и/или лоббистской деятельности бюрократии [Пороховский, 2005]. Открытое лоббирование интересов отдельных рыночных субъектов способствует формированию коррупционных схем, которые относительно редко расследуются в суде, но даже в этом случае окончательное решение принимается не судьей, а членами властной коалиции [Ореховский, 2012]. В связи с этим формулирование и детализация понятия общего экономического интереса в российской экономике представляется актуальной задачей.

\section{Результаты и обсуждение}

Экономические интересы, представляя собой сложную категорию, рассматриваются в различных аспектах. В зависимости от преследуемых целей они подразделяются на частные и общественные. В свою очередь, частные интересы членятся на индивидуально-частные, включающие интересы наемных работников и лиц, обладающих частной собственностью, и предпринимательские, отражающие интересы малого, среднего и крупного бизнеса [Пороховский, 2013].

Носителем общественных интересов может выступать государство или общественные организации, представляющие все общество или отдельные его составляющие. Следует отметить, что общественные интересы, включающие вопросы национальной обороны и безопасности, экологической и правоохранительной деятельности, формирования современной инфраструктуры, несмотря на непосредственную связь с жизнеобеспечением населения, используют результаты предпринимательской деятельности. Однако в данном случае прибыль не распределяется между субъектами, а направляется на достижение общего интереса всех агентов рынка. 
Набор и содержание частных интересов имеет субъективный характер. Любой носитель частных экономических интересов может изменить или прекратить их реализацию, в частности, пересмотреть политику распределения прибыли или отказаться от предпринимательской деятельности. Общественные интересы имеют объективный характер и продиктованы самим фактом существования социального образования. Согласно современным представлениям для развития национальной экономической системы необходимо учитывать и реализовывать как частные, так и общественные интересы. При этом «роль локомотива развития принадлежит частным интересам, а вот скорость движения такого локомотива целиком зависит от общественных интересов» [Пороховский, 2013, с. 53]. В то же время вопросы приоритетности той или иной группы экономических интересов, а также механизмы их согласования являлись предметом работы ученых, начиная с Нового времени. В рамках поставленной цели исследования отметим наиболее значимых представителей мировой экономической науки, сформировавших современные представления о влиянии экономических интересов на развитие конкурентоспособности национальной экономики.

А. де Монкретьен, европейский экономист начала XVII в., в своем известном Трактате о политической экономии 1615 г., введя в обиход термин «политическая экономия», определял управление государством частными интересами как основу национального развития [Левитский, 2015]. Он утверждал, что алгебраическая сумма частных интересов не приводит к позитивному эффекту и экономическому росту. Следовательно, задачей государства является создание условий для их эффективной реализации, что обеспечивает достижение общественных интересов. При этом безусловный приоритет в трудах Монкретьена получили частные интересы, поставленные выше общественных. Современные исследования показывают справедливость этой теории: рациональный подход человека побуждает использовать результаты труда других людей и экономить собственные ресурсы, однако без участия государства общественная эффективность такого процесса низкая [Олсон, 1995]. Кроме того, на данный мо- мент в российской экономике в связи с практической неограниченностью частных экономических интересов после распада СССР массовым стало явление замещения общественных интересов частными интересами субъектов рынка. Это характерно не только для национальной экономики в целом, но и для отдельных хозяйствующих субъектов в частности, например, когда конфликт интересов возникает между собственниками бизнеса и наемным менеджментом.

Первые исследователи проблем экономических интересов - ранние меркантилисты уже вкладывали в приоритеты общего экономического интереса трудовые факторы. Данное положение практически не оспаривалось в работах последующих экономических школ, и в том числе привело к формированию трудовой теории стоимости в марксизме. С учетом новых вызовов, стоящих перед современной Россией и обусловленных как объективными процессами цифровизации мировой экономики, так и финансовыми и технологическими ограничениями, развитие человеческого потенциала и рассмотрение общего экономического интереса в этом контексте представляется оправданным.

В дальнейшем мировоззрение меркантилистов формировалось под влиянием значительно усилившейся роли государства. Представители позднего меркантилизма, в том числе Дж. Стюарт, возлагали достижение общих интересов на государство, носители частных интересов напрямую не участвовали в формировании общественных интересов [Стюарт, 1896]. Следовательно, частые интересы агентов рынка оказывались в подчиненном положении, а общие трактовались исключительно как общественные интересы, связанные с увеличением национального богатства. Однако сегодня основным объектом теории экономических интересов в контексте развития национальной экономики остаются именно частные (индивидуальные) интересы. Сама постановка вопроса об экономических интересах различных субъектов имеет смысл только при возможности их сведения к совокупности индивидуальных интересов. При этом интерес отдельного индивида включается в экономический (интегральный) интерес более высокого порядка. В таком случае на вершине 
данной иерархической структуры находятся общенациональные экономические интересы, определяемые требованиями сбережения нации и сохранения территории (см. рисунок).

Принципиально другой подход характерен для классической экономической школы. Согласно принципу «невидимой руки» А. Смита «экономический человек» преследует в своей деятельности только частные интересы, но в то же время взаимодействие и борьба индивидуальных интересов без дополнительного регулирования приводит к реализации общественных интересов и росту экономики [Смит, 2007]. Следует признать, что теория ученого наиболее полно отражает суть современной капиталистической экономики как сферы столкновения и взаимодействия частных интересов, являющуюся движущей силой поведения хозяйствующих субъектов. Однако на практике эта теория не всегда находит подтверждение в анализе не только отечественных, но и зарубежных ученых [Sen, 1977].

В качестве ярких примеров приведем частные интересы наемных менеджеров, с целью максимизации собственных выгод занижающих официальный размер заработной платы, использующих различные механизмы трансфертного ценообразования с выводом прибыли в офшорные юрисдикции или искусственно создающих высокий уровень задолженности с последующим банкротством организации. А.А. Пороховский отмечает, что и сам Смит признавал невозможность эффективной реализации частных интересов в случае, если государство не обеспечивает соблюдение «правил игры»: «Сильной “невидимой руки" при слабом (в смысле реализации своих экономических функций) государстве не бывает» [Пороховский, 2008, с. 60]. Следствием этого положения является парадоксальная для классической экономической теории ситуация, когда осуществление частных интересов возможно лишь при контролирующей функции государства.

Противоположное явление, соответствующее ничем не ограниченной реализации индивидуальных интересов, негативно сказывается на самих субъектах рынка. В числе вероятных последствий целесообразно выделить: формирование экстерналий (загрязненные воздух, вода и почва, плохое качество инфраструктуры и т. п.); выведение на первый план краткосрочных интересов, ограниченных максимизацией прибыли; увеличение издержек взаимодействия рыночных агентов. Возникновение такой негативной ситуации тем более возможно при отсутствии контроля государства. А. Смит отмечает, что доходность частных лиц находится в обратной зависимости от благосостояния общества. Это приводит к тому, что возрастание нормы прибыли приводит к способности капитала пойти на любые преступления, даже под страхом смертной казни [Маркс и др., 1960]. Следовательно, основной частный экономический интерес - извлечение прибыли - является сильным мотивом для правонарушений. В качестве примера можно привести ослабление государственного контроля реализации частных интересов в 1990-е гг. в России, что привело к повсеместному распространению подкупа должностных лиц, уклонения от уплаты нало-

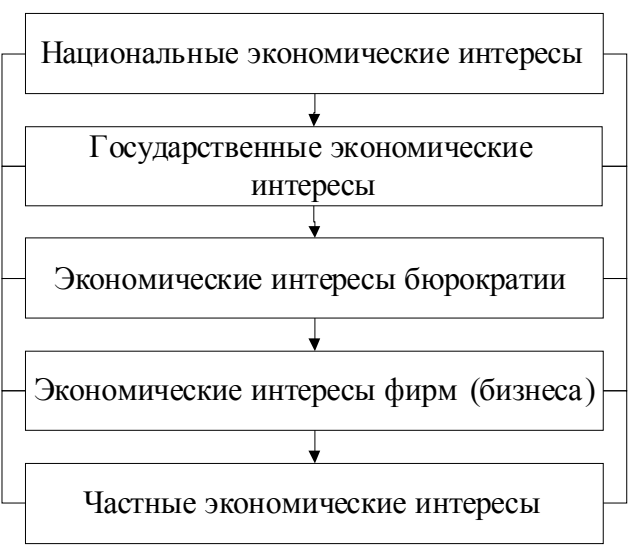

Рисунок. Система экономических интересов в современной экономике

Примечание. Источник: [Альпидовская, 2008]. 
гов и таможенных пошлин с использованием «серых» каналов ввоза импортного оборудования, ограничению конкуренции и монополистической деятельности.

В отсутствии эффективного механизма противодействия таким негативным тенденциям, практически невозможно предотвратить подчинение общественных интересов частным (в том числе бюрократии). В этом случае социально-экономические процессы отклоняются от верного пути развития и замещение экономических интересов наносит вред социально-экономической системе в общем. Следовательно, частный интерес в противовес теории А. Смита может стать антиобщественным. Такие противоречия можно найти повсеместно; например, доход от распространения наркотиков способствует реализации частных, однако не отвечает национальным интересам. Кроме этого, в современной экономической системе присутствуют интересы бюрократии, связанные с ее обслуживанием, что не соответствует частным интересам налогоплательщиков. Особенно остро эта проблема встает при оплате за счет бюджета дорогостоящих служебных квартир и автомобилей, отдыха не только представителей бюрократии, но и членов их семей, а также росте общей численности бюрократического аппарата [Cuervo-Cazurra, 2008].

Дальнейшее развитие теория экономических интересов получила в трудах марксистской школы политической экономии. По К. Марксу, личные интересы, первичные экономические потребности объясняют многие особенности поведения людей. Без удовлетворения или при неполном их удовлетворении экономическая деятельность стимулируется особенно сильно [Маркс и др., 1961]. При этом представителями марксизма рассматривали развитие национальной экономики в контексте реализации частных и общественных интересов через призму индустриальной эпохи, в которой преобладали материальное производство, физический труд, а юридическая свобода работников компенсировалась его экономической зависимостью от работодателя [Пороховский, 2008]. В отличие от представителей классической экономической школы, марксисты не сводили частный экономический интерес исключительно к получению прибыли.
В зависимости от конкретной исторической ситуации, обусловленной общественно-экономической формацией и общей обстановкой, различно и содержание индивидуальных экономических интересов. В своих работах К. Маркс не противопоставлял частные и общественные интересы, так как при определенных условиях и первые, и вторые являются «необходимой формой самоутверждения индивидов» [Маркс и др., 1960, с. 236].

Труды марксистской школы политической экономики свидетельствуют о необходимости включения технологических и инновационных приоритетов в общий экономический интерес. Соответствующий опыт советского периода позволяет заключить непосредственное влияние индустриализации страны на динамику ее развития. Следует отметить, что современные модели новой индустриализации предполагают приоритетное использование данных подходов [Сорокин и др., 2015].

Совершенно иная позиция характерна для германской исторической школы, не воспринимавшей приоритетность частного экономического интереса. Ее представители ввели в теорию необходимость учета, помимо экономических, неэкономических факторов, прежде всего, социальных явлений. Следовательно, основным объектом анализа становится не индивидуальный человек, а исторически сложившаяся общность людей, проживающих на одной территории - нация. В трудах германской школы детализированы факторы, приводящие к реализации частных (эгоистических) и общественных (альтруистических) интересов. Естественные потребности человека формируют частные интересы индивида, в то время как исторические особенности нации приводят к формированию у индивидов чувств общности справедливости - источника общественных интересов. В работах представителей германской исторической школы прослеживается, что для нации духовные ценности стоят над материальными благами. Реализуя свои экономические интересы, нация приводит общество к гармонии, обеспечивает необходимый баланс духовных и материальных ценностей, в то время как «человек экономический» является рабом своих потребностей [Мусин, 2006]. 
Представители германской исторической школы, отмечая необходимость учета национальной специфики стран при разработке стратегий их развития, в контексте российской специфики предполагают включение в понятие общего экономического интереса факторов национальной самодостаточности. Более подробно аспекты формирования самодостаточной экономической системы в контексте повышения конкурентоспособности российской экономики представлены в современных работах (см., например: [Цикин, 2018]).

В работах маржиналистов произошел откат к принципу приоритета частных экономических интересов и провозглашению объектов анализа индивидуального человека. Основным частным интересом представляется извлечение прибыли, и даже альтруистические поступки людей трактуются как проявление эгоизма. Общественные интересы вновь предстают как сумма частных экономических интересов, при этом отвергаются национальные и исторические факторы. Интересен подход маржиналистов к обоснованию появления денег в обществе: их возникновение произошло вследствие непреднамеренных и нескоординированных действий отдельных индивидов, движимых частными экономическими интересами. Следовательно, деньги являются выражением общественного интереса, сформированного индивидуальными интересами отдельных людей [Менгер, 2008].

А. Маршалл в своих работах предпринял попытку синтезировать подходы классической, исторической и маржиналистской экономических школ и отойти от деятельности «человека экономического» К «нормальному функционированию общества» - взаимодействию совокупности индивидов [Маршалл, 1983]. Основатель неоклассической школы возвращает в сферу анализа исторические, национальные и классовые факторы, а также альтруистические мотивы человеческой деятельности. При этом основным частным экономическим интересом провозглашается прибыль, которую человек может израсходовать на эгоистические или альтруистические потребности. Согласование частных и общественных экономических интересов А. Маршалл видел в процессе рыночного взаимодействия спроса и предложения, когда сбалансированная цена уравнове- шивает спрос, формируемый частными экономическими интересами, и предложение, характеризуемое общественными затратами. В теории ученого этот подход является центральным, сближающим его с представителями германской исторической школы, также искавшими закономерности в поведении индивидов на основании их привычек и обычаев.

Институционалисты отвергают концепцию «человека экономического», который в своих действиях руководствуется исключительно извлечением прибыли и минимизацией затрат. Реальная деятельность индивида находится под влиянием большого количества неэкономических факторов, включающих возраст, социальный класс, уровень образования, отношения собственности. Т. Веблен в основу поведения индивидов ставит совокупность характера и инстинктов, которые включают привычки и обычаи, обусловливающие демонстративное потребление [Веблен, 1984]. При этом последнее - нежелательное социальное явлением, связанное с необоснованными расходами, вызванными мнимыми интересами (например, следование моде).

Институционалисты отвергали возможность дост ижения общественных интересов при реализации частных экономических интересов в условиях саморегуляции экономики. Необходимым условием достижения общественных интересов является наличие социально-экономических институтов, обусловливающих основной частный экономический интерес - рост социального статуса. Соответствующая деятельность индивидов приводит к реализации творческого начала человека и повышению конкурентоспособности экономики. Следовательно, в общий экономический интерес России необходимо включить социальные и институциональные приоритеты. Вместе с тем сама сущность институтов, связанная с их формированием на основе ретроспективного опыта, приводит к тому, что технологическое развитие становится ограниченным по динамике. Это свидетельствует о недопустимости развития институциональных факторов в ущерб прочим (технологическим и инновационным).

Представителем школы институционализма Дж.К. Гэлбрейтом сформулированы современные аспекты теории экономических 
интересов. Сегодня максимизация дохода перестает играть основополагающую роль для высокооплачиваемых специалистов, значительно усиливается роль экологии, образования, инфраструктуры и социального обеспечения в иерархии общественных интересов, что в том числе позволяет включить в общий экономический интерес инфраструктурные приоритеты. В своих работах Гэлбрейт исследовал новые конфликты экономических интересов управляющих, собственников корпораций и населения. Выходом из сложившихся противоречий должно стать усиление роли государства как гаранта общественных интересов и расширение его социальных функций [Гэлбрейт, 2004].

Дж.М. Кейнс в своих исследованиях впервыепроводит анализ экономических интересов различных групп (частных лиц, фирм, общества) на макроуровне, воспринимая национальную экономическую систему как единое целое. Благодаря ученому в современную теорию экономических интересов вошли анализ норм накопления и потребления, формирующих концепцию эффективного спроса. Несоответствие совокупного спроса и предложения приводит к ситуации, в которой ущемляются интересы предпринимателей, а вследствие этого и наемных работников [Кейнс, 2000]. С опорой на работы Кейнса возможно формулирование общего экономического интереса как интереса национальной экономической системы, опирающейся на ряд ранее выявленных приоритетов, реализация которого возникает при активном участии государства.

На основании анализа эволюции теорий экономических интересов следует признать, что до сих пор не выработана единая точка зрения относительно данного понятия. Главной причиной является необходимость формирования четкой взаимосвязи цели (достижение общего экономического интереса) и механизма ее реализации. Однако изменяющиеся условия хозяйствования и частные особенности национальных экономик диктуют необходимость разработки индивидуальных подходов к достижению общих экономических интересов.

Сегодня можно выделить два основных подхода к согласованию частных и общественных экономических интересов. Первый построен на совершенствовании существующего государственного устройства, при этом разрабатывается модель «идеального государства». Второй подход отвергает государственную форму координации частных и общественных интересов, при этом выходом является снижение роли государства, последующее преодоление государственности и построение «идеального общества» [Иванов, 2005]. Не отклоняя последнее, следует отметить, что государство со времени своего возникновения является основным институтом, обеспечивающим жизнедеятельность общества. В связи с этим согласование частных и общественных интересов целесообразно проводить на основе взвешенной государственной политики.

Для определения баланса общественных и частных интересов рационально использовать понятие общего интереса [Конвенция ... , 1950]. Данное понятие, достижение которого необходимо для формирования и развития конкурентоспособности национальной экономики, невозможно назвать простым интегрированием экономических интересов государства, организаций и частных лиц по ряду причин. Во-первых, несмотря на то, что государство, организации и физические лица являются элементами одной экономической системы, их интересы часто прямо противоречат друг другу. Так, экономическому интересу организации в расширении производства и социальном обеспечении работников противостоят государственные интересы, состоящие в увеличении налоговых платежей, и интересы инвесторов фирмы, заключающиеся в увеличении суммы дивидендных выплат. Особо сильное противоречие экономических интересов государства, организаций и их учредителей наблюдается при ликвидации или реорганизации юридических лиц. Во-вторых, общие экономические интересы - это интересы более высокого порядка, нежели государства, организаций и инвесторов, которые носят подчиненный характер по отношению к общим интересам.

Целесообразным считаем предложить следующую трактовку: общий экономический интерес - это интерес социально-экономической системы, выражающийся в повышении национальной конкурентоспособности на осно- 
ве социальных, инновационных, технологических, трудовых, инфраструктурных, институциональных приоритетов (а также самодостаточности экономики), которые не меняются в течение длительного, согласованного агентами рынка срока. Достижение общего экономического интереса в современных российских условиях предполагает активное участие государства, определяющего тот коридор действий «невидимой руки рынка», который обеспечит повышение национальной конкурентоспособности. В этом и состоит принципиальная увязка частных и общественных интересов [Пороховский, 2008].

В заключение следует признать трудность самой постановки вопроса об общих экономических интересах в современных российских условиях. Развитие российской экономики, базирующееся на достижении общих экономических интересов, может быть реализовано только при опоре на некоррумпированных представителей бюрократии. Однако вопросы избавления российского общества от коррупции ввиду своей специфики должны рассматриваться в отдельных исследованиях (см., например: [Добрынин, 2012]).

\section{Выводы и рекомендации}

В результате выполненных исследований детализировано понятие общего экономического интереса как интереса российской экономической системы в целом. На основе анализа подходов представителей основных экономических школ к согласованию частных и общественных интересов, а также приоритетов развития национальных экономик установлена необходимость включения в общий экономический интерес России социальных, инновационных, технологических, трудовых, инфраструктурных, институциональных факторов и самодостаточности экономики.

Согласование экономических интересов субъектов рынка целесообразно проводить на основе взвешенной государственной политики, предполагающей усиление роли государства. В данном контексте роль государства в достижении общего экономического интереса состоит в создании такого коридора действий частных экономических агентов, который с учетом механизмов авторегуляции эко- номики обеспечил бы повышение национальной конкурентоспособности.

Результаты исследования могут быть использованы при разработке стратегий повышения конкурентоспособности российской экономики в условиях хаотизации внешней среды, вызванной финансовыми и технологическими санкционными ограничениями, усугубленными дисбалансом в системе национальных экономических отношений.

\section{ПРИМЕЧАНИЕ}

${ }^{1}$ Статья опубликована при поддержке гранта Российского фонда фундаментальных исследований (РФФИ) «Проблемы конфигурации глобальной экономики XXI века: идея социально-экономического прогресса и возможные интерпретации, № 18010-00877 А».

The work is supported by "Issues of Configuration of the Global Economy of the $21^{\text {st }}$ Century: The Idea of Socio-Economic Progress and Possible Interpretations, no. 18-010-00877 A" Russian Foundation for Basic Research (RFBR) grant.

\section{СПИСОК ЛИТЕРАТУРЫ}

Альпидовская, М. Л. Теория бюрократии: экономический аспект / М. Л. Альпидовская. - М. : Красная звезда, 2008. - 176 с.

Андреев, А. Л. Бюрократия: эрозия компетентности или нравственный кризис? / А. Л. Андреев // Мониторинг общественного мнения: экономические и социальные перемены. - 2006. № 1 (77). - С. 27-37.

Афонцев, С. Российский крупный бизнес в условиях глобального кризиса / С. Афонцев, С. Дж. Ли // Вопросы экономики. - 2013. № 5. - С. 40-55.

Веблен, Т. Теория праздного класса / Т. Веблен. М. : Прогресс, 1984. - 367 с.

Гэлбрейт, Дж. Новое индустриальное общество / Дж. Гэлбрейт. - М. : АСТ, 2004. - 225 с.

Добрынин, Л. А. Российская модель системной коррупции и стратегия ее преодоления / Л. А. Добрынин // Экономика и управление. - 2012. № 6. - С. 30-35.

Дози, Дж. Экономическая координация и динамика: некоторые особенности альтернативной эволюционной парадигмы / Дж. Дози // Вопросы экономики. - 2012. - № 12. - С. 31-60.

Иванов, С. А. Социальное партнерство как феномен цивилизации / С. А. Иванов // Журнал 
социологии и социальной антропологии. 2005. - Т. 8, № 3. - С. 79-99.

Кейнс, Дж. Общая теория занятости, процента и денег. Избранное / Дж. Кейнс. - М. : Эксмо, 2000. $-960 \mathrm{c}$.

Конвенция «О защите прав человека и основных свобод». - Электрон. текстовые дан. - Режим доступа: https://base.garant.ru/2540800/ (дата обращения: 15.02.2019). - Загл. с экрана.

Левитский, В. Ф. История политической экономии в связи с историей хозяйственного быта: С древнейших времен до конца XIX века / В. Ф. Левитский. -М. : ЛИБРОКОМ, 2015. -498 с.

Маркс, К. Собр. соч. / К. Маркс, Ф. Энгельс. - М. : Гос. изд-во полит. лит., 1960. - Т. 23. - 907 с.

Маркс, К. Собр. соч. / К. Маркс, Ф. Энгельс. - М. : Гос. изд-во полит. лит., 1961. - Т. 46. - 956 с.

Маршалл, А. Принципы политической экономии / А. Маршалл. - М. : Прогресс, 1983. -415 с.

Менгер К. Основания политической экономии / К. Менгер. - М. : Директмедиа Паблишинг, 2008. -495 c.

Мусин, М. М. Управление экономическими интересами / М. М. Мусин. - М. : Гардарики, 2006. $-287 \mathrm{c}$.

Олсон, М. Логика коллективных действий: общественные блага и теория групп / М. Олсон. М. : Фонд экономической инициативы, 1995. $165 \mathrm{c}$.

Ореховский, П. А. Право на оспаривание, патронклиентские сети и коррупция / П. А. Ореховский // Вопросы экономики. - 2012. - № 11. C. 101-117.

Пороховский, А. А. Ключевые принципы рыночного развития: двадцать лет в России / А. А. Пороховский // Мир перемен. - 2013. - № 1. С. 51-57.

Пороховский, А. А. О российской модели рыночной экономики / А. А. Пороховский // Вестник Московского университета. Серия 6, Экономика. - 2005. - № 1. - С. 27-40.

Пороховский, А. А. Эволюция рыночной экономики в зеркале политической экономии / А. А. Пороховский // Российский экономический журнал. -2008. - № 1-2. - С. 57-71.

Смит, А. Исследование о природе и причинах богатства народов / А. Смит. - М. : Эксмо, 2007. $960 \mathrm{c.}$

Сорокин, Д. Е. Условия и факторы эффективной реиндустриализации и промышленной политики России / Д. Е. Сорокин, С. А. Толкачев // Экономическое возрождение России. - 2015. - № 4 (46). - С. 85-97.

Стюарт, Дж. Ст. Основания политической экономии / Дж. Ст. Стюарт. - Киев : Тип. И.И. Чоколова, 1896. -883 c.
Цикин, А. М. Самодостаточность как основа повышения конкурентоспособности российской экономики / А. М. Цикин // Теоретическая экономика. - 2018. -№ 2. - С. 81-87.

Cuervo-Cazurra, A. Better the devil you don't know: Types of corruption and FDI in transition economies / A. Cuervo-Cazurra // Journal of International Management. - 2008. - Vol. 14, № 1. - P. 12-27.

Sen, A. K. Rational fools: A critique of the behavioral foundations of economic theory / A. K. Sen // Philosophy and Public Affairs. - 1977. - Vol. 6, № 4. -P. 317-344.

\section{REFERENCES}

Alpidovskaya M.L. Teoriya byurokratii: ekonomicheskiy aspect [Theory of Bureaucracy: Economic Aspect]. Moscow, Krasnaya Zvezda Publ., 2008. 176 p.

Andreev A.L. Byurokratiya: eroziya kompetentnosti ili nravstvennyy krizis? [Bureaucracy: Erosion of Competence or Moral Crisis?]. Monitoring obshchestvennogo mneniya: ekonomicheskie i socialnye peremeny, 2006, no. 1 (77), pp. 27-37.

Afontsev S., Li S.Dzh. Rossiyskiy krupnyy biznes v usloviyakh globalnogo krizisa [Russian Big Business in Global Crisis]. Voprosy ekonomiki, 2013, no. 5, pp. 40-55.

Veblen T. Teoriya prazdnogo klassa [Idle Class Theory]. Moscow, Progress Publ., 1984. 367 p.

Galbraith J. Novoe industrialnoe obshchestvo [New Industrial Society]. Moscow, AST Publ., 2004. $225 \mathrm{p}$.

Dobrynin L.A. Rossiyskaya model sistemnoy korruptsii i strategiya ee preodoleniya [Russian Model of System Corruption and Strategy to Overcome It]. Ekonomika i upravlenie, 2012, no. 6, pp. 30-35.

Dozi Dzh. Ekonomicheskaya koordinatsiya i dinamika: nekotorye osobennosti alternativnoy evolyutsionnoy paradigm [Economic Coordination and Dynamics: Some Features of Alternative Evolutionary Paradigm]. Voprosy ekonomiki, 2012, no. 12, pp. 31-60.

Ivanov S.A. Sotsialnoe partnerstvo kak fenomen tsivilizatsii [Social Partnership as Phenomenon of Civilization]. Zhurnal sotsiologii i sotsialnoy antropologii, 2005, vol. 8, no. 3, pp. 79-99.

Keynes J. Obshchaya teoriya zanyatosti, protsenta $i$ deneg. Izbrannoe [General Theory of Employment, Interest and Money. Favorites]. Moscow, Eksmo Publ., 2000. 960 p.

Konventsiya "O zashchite prav cheloveka $i$ osnovnykh svobod» [Convention on the 
Protection of Human Rights and Fundamental Freedoms]. URL: https://base.garant.ru/2540800/ (Accessed 15 February 2019).

Levitskiy V.F. Istoriya politicheskoy ekonomii v svyazi s istoriey hozyaystvennogo byta: $S$ drevneyshikh vremen do kontsa XIX veka [History of Political Economy in Connection with History of Economic Life: From Ancient Times to End of XIX Century]. Moscow, LIBROKOM Publ., 2015. 498 p.

Marx K., Engels F. Sobranie sochineniy [Collected Works]. Moscow, Gosudarstvennoe izdatelstvo politicheskoy literatury, 1960, vol. 23.907 p.

Marx K., Engels F. Sobranie sochineniy [Collected Works]. Moscow, Gosudarstvennoe izdatelstvo politicheskoy literatury, 1961, vol. 46. 956 p.

Marshall A. Printsipy politicheskoy ekonomii [Principles of Political Economy]. Moscow. Progress Publ., 1983. 415 p.

Menger K. Osnovaniya politicheskoy ekonomii [Foundations of Political Economy]. Moscow, Directmedia Publ., 2008. 495 p.

Musin M.M. Upravlenie ekonomicheskimi interesami [Management of Economic Interests]. Moscow, Gardariki Publ., 2006. 287 p.

Olson M. Logika kollektivnyhh deystviy: obshchestvennye blaga i teoriya grupp [Logic of Collective Action: Public Goods and Group Theory]. Moscow, Fond ekonomicheskoy initsiativy Publ., 1995. 165 p.

Orekhovskiy P.A. Pravo na osparivanie, patronklientskie seti i korruptsiya [Right to Challenge, Patron-Client Networks and Corruption]. Voprosy ekonomiki, 2012, no. 11, pp. 101-117.

Porokhovskiy A.A. Klyuchevye printsipy rynochnogo razvitiya: dvadtsat let v Rossii [Key Principles of Market Development: Twenty Years in Russia]. Mir peremen, 2013, no. 1, pp. 51-57. Porokhovskiy A.A. O rossiyskoy modeli rynochnoy ekonomiki [About Russian Market Economy Model]. Vestnik Moskovskogo universiteta. Seriya 6, Ekonomika, 2005, no. 1, pp. 27-40.

Porokhovskiy A.A. Evolyutsiya rynochnoy ekonomiki $\mathrm{v}$ zerkale politicheskoy ekonomii [Evolution of Market Economy in Mirror of Political Economy]. Rossiyskiy ekonomicheskiy zhurnal, 2008, no. 1-2, pp. 57-71.

Smith A. Issledovanie o prirode $i$ prichinakh bogatstva narodov [Research on Nature and Causes of Wealth of Nations]. Moscow, Eksmo Publ., 2007.960 p.

Sorokin D.E., Tolkachev S.A. Usloviya i faktory effektivnoy reindustrializatsii i promyshlennoy politiki Rossii [Conditions and Factors of Effective Re-industrialization and Industrial Policy of Russia]. Ekonomicheskoe vozrozhdenie Rossii, 2015, no. 4 (46), pp. 85-97.

Stuart J. Osnovaniya politicheskoy ekonomii [Foundations of Political Economy]. Kiev, I.I. Chokolov Publ., 1896. 883 p.

Tsikin A.M. Samodostatochnost kak osnova povysheniya konkurentosposobnosti rossiyskoy ekonomiki [Self-Sufficiency as a Basis for Improving the Competitiveness of the Russian Economy]. Teoreticheskaya ekonomika, 2018, no. 2, pp. 81-87.

Cuervo-Cazurra A. Better the Devil You Don't Know: Types of Corruption and FDI in Transition Economies. Journal of International Management, 2008, vol. 14, no. 1, pp. 12-27.

Sen A.K. Rational Fools: A Critique of the Behavioral Foundations of Economic Theory. Philosophy and Public Affairs, 1977, vol. 6, no. 4, pp. 317-344.

\section{Information about the Author}

Aleksej M. Tsikin, Candidate of Sciences (Chemistry), Doctoral Student, Department of Economic Theory, Financial University under the Government of the Russian Federation, Leningradsky Prosp., 49, 125993 Moscow, Russian Federation, tsikinalexey@mail.ru, https://orcid.org/0000-0003-4383-0373

\section{Информация об авторе}

Алексей Максимович Цикин, кандидат химических наук, докторант департамента экономической теории, Финансовый университет при Правительстве РФ, Ленинградский просп., 49, 125993 г. Москва, Российская Федерация, tsikinalexey@mail.ru, https://orcid.org/0000-0003-4383-0373 